\title{
Regulation of the Intermediate Filament Protein Nestin at Rodent Neuromuscular Junctions by Innervation and Activity
}

\author{
Hyuno Kang, ${ }^{1}$ Le Tian, ${ }^{1}$ Young-Jin Son, ${ }^{1}$ Yi Zuo, ${ }^{1}$ Diane Procaccino, ${ }^{1}$ Flora Love, ${ }^{1}$ Christopher Hayworth, ${ }^{1}$ \\ Joshua Trachtenberg, ${ }^{1}$ Michelle Mikesh, ${ }^{1}$ Lee Sutton, ${ }^{1}$ Olga Ponomareva, ${ }^{1}$ John Mignone, ${ }^{2}$ Grigori Enikolopov, ${ }^{2}$ \\ Mendell Rimer, ${ }^{1}$ and Wesley Thompson ${ }^{1}$ \\ ${ }^{1}$ Section of Neurobiology, Institute of Neuroscience, and Institute for Cell and Molecular Biology, University of Texas, Austin, Texas 78712 , and ${ }^{2}$ Cold \\ Spring Harbor Laboratories, Cold Spring Harbor, New York 11724
}

The intermediate filament nestin is localized postsynaptically at rodent neuromuscular junctions. The protein forms a filamentous network beneath and between the synaptic gutters, surrounds myofiber nuclei, and is associated with Z-discs adjacent to the junction. In situ hybridization shows that nestin mRNA is synthesized selectively by synaptic myonuclei. Although weak immunoreactivity is present in myelinating Schwann cells that wrap the preterminal axon, nestin is not detected in the terminal Schwann cells (tSCs) that cover the nerve terminal branches. However, after denervation of muscle, nestin is upregulated in tSCs and in SCs within the nerve distal to the lesion site. In contrast, immunoreactivity is strongly downregulated in the muscle fiber. Transgenic mice in which the nestin neural enhancer drives expression of a green fluorescent protein (GFP) reporter show that the regulation in SCs is transcriptional. However, the postsynaptic expression occurs through enhancer elements distinct from those responsible for regulation in SCs. Application of botulinum toxin shows that the upregulation in tSCs and the loss of immunoreactivity in muscle fibers occurs with blockade of transmitter release. Extrinsic stimulation of denervated muscle maintains the postsynaptic expression of nestin but does not affect the upregulation in SCs. Thus, a nestin-containing cytoskeleton is promoted in the postsynaptic muscle fiber by nerve-evoked muscle activity but suppressed in tSCs by transmitter release. Nestin antibodies and GFP driven by nestin promoter elements serve as excellent markers for the reactive state of SCs. Vital imaging of GFP shows that SCs grow a dynamic set of processes after denervation.

Key words: transgenic; synaptic gene expression; terminal Schwann cell; denervation; paralysis; muscle stimulation

\section{Introduction}

The muscle fiber membrane at the neuromuscular junction $(\mathrm{nmj})$ is highly specialized like the postsynaptic membrane at all synapses (cf. Sanes and Lichtman, 2001). The junctional membrane is regularly folded into "junctional folds," and proteins specialized for efficient synaptic transmission, acetylcholine re-

Received Feb. 12, 2007; revised April 20, 2007; accepted April 25, 2007.

This work was supported by National Institutes of Health Grants NS20480 (W.T.), GM065797 (M.R.), and NS032764 (G.E.). We thank Holly Cline for suggesting the use of the GFP mice in this study and Jeff Lichtman for use of his confocal microscopes.

Correspondence should be addressed to Wesley Thompson, Section of Neurobiology, University of Texas, Austin, TX 78712.E-mail:wes@mail.utexas.edu.

H. Kang's present address: Department of Molecular and Cellular Biology, Harvard University, Cambridge, MA 02138.

L. Tian's present address: Department of Physiology and Biophysics, University of Washington, Seattle, WA 98195.

Y.-J. Song's present address: Department of Neurobiology and Anatomy, Drexel University College of Medicine, Philadelphia, PA 19129.

Y. Zuo's present address: Department of Molecular, Cell, and Developmental Biology, University of California, Santa Cruz, Santa Cruz, CA 95064.

J. Trachtenberg's present address: Department of Neurobiology, University of California, Los Angeles, Los Angeles, CA 90095.

J. Mignone's present address: Department of Internal Medicine, University of Washington, Seattle, WA 98195. D01:10.1523/JNEUROSCI.0621-07.2007

Copyright $\odot 2007$ Society for Neuroscience $\quad$ 0270-6474/07/275948-10\$15.00/0 ceptors (AChRs) and sodium channels, are concentrated at specific locations in the membranes of these folds. A specialized basal lamina with region-specific molecules is also present. A large number of cytoskeletal proteins and proteins suggested to provide links to the cytoskeleton are concentrated here and may be involved in generating the folds and anchoring their specialized components in place (Froehner et al., 1987). Our understanding of the molecular composition of this synaptic structure and how it is put together is incomplete.

Intermediate filaments (IFs) are a diverse class of filamentous proteins (Coulombe and Wong, 2004), some of which are concentrated at the nmj. IFs and IF-like proteins found at the nmj include desmin (Sealock et al., 1989), a $51 \mathrm{kDa}$ IF-like protein in the frog (Burden, 1982), the 3G2/4E2 IF-like antigen concentrated in rats (Astrow et al., 1992, 1994), and a lamin B-like protein in Torpedo electrocytes (Cartaud et al., 1989). The functions of IF proteins at the nmj are unknown; however, their putative roles include the structural or functional organization of junctional components, protection of the cellular components from injury during contraction, immobilization of AChRs via interactions with other cytoskeletal elements, and the localization of subsynaptic nuclei (Ellisman et al., 1976; Hirokawa and Heuser, 1982; Froehner et al., 1987; Sealock et al., 1989). 
Nestin is a large, $200 \mathrm{kDa}$, IF protein originally identified by the rat 401 antibody (Hockfield and McKay, 1985; Lendahl et al., 1990). Nestin has been shown to be expressed in a wide variety of cells, including cells in the proliferative zone of the rat neural tube (Hockfield and McKay, 1985), radial glia (Hockfield and McKay, 1985), O-2A progenitor cells (Gallo and Armstrong, 1995), Schwann cells (SCs) (Hockfield and McKay, 1985; Friedman et al., 1990), reactive astrocytes (Clarke et al., 1994), and developing skeletal muscle (Hockfield and McKay, 1985; Lendahl et al., 1990; Sejersen and Lendahl, 1993; Kachinsky et al., 1994). The nestin present in developing muscle fibers is reported to be essentially replaced postnatally by another IF, desmin (Sejersen and Lendahl, 1993; Kachinsky et al., 1994).

Vaittinen et al. (1999) reported that nestin is localized to the muscle fiber underneath the rat $\mathrm{nmj}$ and at myotendinous junctions, that denervation increased nestin expression in muscle but did not effect expression at the myotendinous junctions, and that denervation resulted in an upregulation of nestin in SCs of axotomized nerve (Friedman et al., 1990). Similarly, Carlsson et al. (1999) have used immunoelectron microscopy to show nestin IFs in the sarcoplasm between junctional folds, even in mice that lack expression of desmin, the IF that would be expected to form protodimers with nestin. Previous observations from our laboratory (Kopp and Thompson, 1998; Kang et al., 2001) have reported some similar findings but also some significant differences. Here we expand on these previous reports and report several novel findings. First, by analyzing the distribution of nestin using high-resolution confocal microscopy, we show that a nestin matrix is positioned beneath the bottoms of the junctional folds and extends into the sarcoplasm between folds. Second, we report that a monoclonal antibody (mAb $4 \mathrm{E} 2)$ produced several years ago (Astrow et al., 1992, 1994) recognizes a unique epitope present on a truncated nestin protein. Third, by investigating how innervation affects nestin expression, we show that denervation, contrary to a previous report, leads to a downregulation at the nmj in adult muscle and, in agreement with previous reports, an upregulation in SCs. We provide evidence that, in muscle, nestin expression is activity dependent; it can be maintained in a denervated muscle by extrinsic stimulation and in innervated muscle is diminished by paralysis. In terminal SCs (tSCs), a component of the regulation involves transmitter release. We show using in situ hybridization that nestin is transcribed selectively by synaptic myonuclei. Using a green fluorescent protein (GFP) transgene regulated by specific nestin control elements, we show that nestin expression in SCs is under transcriptional control. Last, we show nestin-GFP transgenic mice can be imaged vitally to monitor the growth and dynamics of SC processes after denervation.

\section{Materials and Methods}

Animals and surgery. Rats and mice were anesthetized with ketamine/ xylazine as described previously (Zuo et al., 2004) for survival surgeries or with Nembutal $(200 \mathrm{mg} / \mathrm{kg})$ for terminal experiments. For muscle denervations, either a $1 \mathrm{~mm}$ piece of the sciatic nerve was resected or the nerve was crushed three times between the smooth tips of \#5 Dumont forceps. Wounds were closed with suture.

Antibodies, immunolabeling, and microscopy. Immunolabeling procedures have been described previously (Son and Thompson, 1995a). Briefly, four different anti-nestin antibodies were used: rat 401, a mouse monoclonal that recognizes an epitope in the $\mathrm{N}$-terminal portion of the fourth exon of nestin [Developmental Studies Hybridoma Bank (DSHB), University of Iowa, Iowa City, IA] (Lendahl et al., 1990); antibody SCRR-1001, a rabbit polyclonal directed against an 18 amino acid peptide at the very $\mathrm{N}$ terminus of nestin (American Type Culture Collec- tion, Manassas, VA); 4E2 [a mouse monoclonal prepared in this laboratory (Astrow et al., 1992) available from DSHB] whose properties are further described below; and antiserum 130, a rabbit antibody directed against a bacterially produced fusion peptide in the C-terminal tail of nestin (a gift from Dr. Ron McKay, National Institute of Neurological Disorders and Stroke/National Institutes of Health, Bethesda, MD) (Dahlstrand et al., 1992). SCs were labeled with a polyclonal antibody to S100 (DakoCytomation, Carpinteria, CA); axons and nerve terminals were labeled by a combination of two mouse monoclonals directed against neurofilament and synaptic vesicle proteins ( $2 \mathrm{H} 3$ and SV2, respectively, DSHB). Antibodies were also used to label sodium channels (SP19; Sigma, St. Louis, MO) and to label ankyrin G (33-8800; Zymed Laboratories, South San Francisco, CA). A variety of secondary antibodies directed against mouse and rabbit primaries and conjugated to fluorescein, rhodamine, Texas Red, and the Cy dye Cy5 were used as described previously (Son and Thompson, 1995a). Two isotype-specific anti-mouse secondaries were used to enable double labeling of mouse $\mathrm{IgG}_{1}$ and $\mathrm{IgG}_{2 \mathrm{~b}}$ primary antibodies in the same samples. Rhodamine-, Texas Red-, and Cy5-conjugated $\alpha$-bungarotoxin (Invitrogen, Carlsbad, $\mathrm{CA})$ were used to label AChRs at nmjs. Muscles were dissected and generally fixed in $4 \%$ paraformaldehyde except for muscles labeled with $4 \mathrm{E} 2$ and rat 401 , which were fixed in methanol at $-20^{\circ} \mathrm{C}$ or fixed briefly with $1 \%$ paraformaldehyde. Labeling was performed using the whole muscle; a sheet of fibers was subsequently dissected from the muscle surface and mounted on slides in aqueous mounting medium for observation. Images were captured using a Leica (Nussloch, Germany) DMR microscope with $40 \times, 63 \times$, and $100 \times$ oil immersion objectives [numerical apertures (NAs) of 1.0, 1.32, and 1.3, respectively], a cooled CCD camera (CoolSnap HQ; Roper Scientific, Tucson, AZ), and a computer running IP Lab software (Scanalytics, Fairfax, VA). Some images were collected using a Leica confocal microscope with a $63 \times, 1.4$ NA objective or an Olympus Optical (Tokyo, Japan) Fluoview 1000 with $60 \times$ and $100 \times$ objectives, both at 1.45 NA. Contrast and brightness of images were adjusted in Photoshop (Adobe Systems, San Jose, CA).

In all cases, assessments of nestin immunoreactivity were done by simultaneously processing both manipulated muscles and control muscles (most commonly, the contralateral muscle). Our common practice was to immunostain both muscles with the same reagents in the same microcentrifuge tube. All statements about differences in labeling intensity come from side-by-side microscopic examination of the material using the same illumination conditions, camera gains, and exposure times. Unless noted otherwise, the intensity differences could be discerned without effort, and no attempt was made to quantify the differences.

Transgenic mice. Transgenic mice constructed with the coding sequences for cytoplasmic, enhanced GFP (EGFP) inserted between $5.8 \mathrm{~kb}$ of the nestin promoter and a $1.8 \mathrm{~kb}$ fragment containing the second intron were used; these mice have been reported previously (Mignone et al., 2004). A second transgenic line with EGFP replaced with a nuclearlocalized cyan fluorescent protein (CFP) was prepared in the Enikolopov laboratory and was used in a single set of experiments. Nestin-EGFP transgenic mice were identified either by PCR for GFP or by passing the mice under a fluorescence dissecting scope and scoring for the presence of fluorescence in the lens of the eye or in hair follicles (Mignone et al., 2004).

Vital imaging. Procedures for vital imaging were identical to those described previously (Zuo et al., 2004).

In situ hybridization. In situ hybridization with digoxigenin-labeled riboprobes was performed as described previously (Rimer et al., 2004). The nestin probe was generated by PCR using adult rat skeletal muscle cDNA as template. The forward primer contained T7 promoter sequences upstream of the nestin-specific sequence: $5^{\prime}$ ACTGCAGAAGAGGACCTGGA-3'. The reverse primer contained T3 promoter sequences upstream of the nestin-specific sequence: $5^{\prime}$ AGTTCCCACTCCTGTGGTTG-3'. T3 RNA polymerase was used to make antisense probes; T7 RNA polymerase was used to make sense probes. The probe for $A C h R \alpha$ was described previously (Rimer et al., 2004). Cholinesterase activity was visualized by histochemical staining (Karnovsky, 1964). 
Botulinum toxin paralysis. Botulinum toxin type A (10-20 ng dissolved in PBS containing $0.2 \%$ gelatin) was applied to the surface of the sternomastoid muscle of mice or to the soleus muscle of rats and left in place for $5 \mathrm{~min}$ as described previously (Love and Thompson, 1999). At the time of the terminal experiment, the twitch response to nerve stimulation was noted. In rat soleus muscles, this twitch was absent and the muscle was considered effectively blocked. In mouse sternomastoid muscles, two treated muscles connected to tension transducers yielded 2 and $6 \%$ of the tetanic force elicited by direct muscle stimulation, showing that neuromuscular transmission had been suppressed below threshold for most fibers in these muscles.

Muscle stimulation. The sciatic nerve in the right leg was resected. In six rats, stimulating wires were placed at the ends of the soleus muscle in this leg, led underneath the skin to a connector attached to cranium, and attached to a rotating mercury contact that allowed the animals free movement within their caging (Love et al., 2003). Stimuli were administered as described previously. At the time of the terminal experiment, muscles were connected to a strain gauge, and their sensitivity to bathapplied acetylcholine chloride was tested as described previously (Love et al., 2003). Successful stimulations substantially reduced muscle atrophy, and stimulated muscles underwent contractures at 10- to 100-fold higher concentrations of acetylcholine than muscles that were not stimulated. Unsuccessful stimulations were rare and were associated with loss of placement of electrodes or broken stimulus leads.

Monoclonal antibody 4E2. Previous work described the generation of a mouse monoclonal antibody (4E2) that recognizes an epitope concentrated at the nmj that disappears after denervation but that then appears in tSCs (Astrow et al., 1994). On immunoblots, this antibody recognizes an $\sim 48 \mathrm{kDa}$ band, of acidic $\mathrm{pI}(5.6)$. In an attempt to identify the epitope, we isolated immunoreactive protein spots from two-dimensional PAGE, digested this protein with the endoproteinase Lys-C, and microsequenced the most prominent peptide separated by HPLC. This yielded a 12 amino acid peptide identical in sequence to positions $261-272$ in the rod domain of rat nestin (for structure, see Lendahl et al., 1990). We conclude, on the basis of this peptide sequence and the identical immunostaining obtained with 4E2 and the other nestin antibodies (data not shown), that $4 \mathrm{E} 2$ recognizes nestin. The protein band recognized by antibody 4E2, however, is of considerably lower molecular weight than full-length nestin (supplemental Fig. 1, available at www.jneurosci.org as supplemental material). The polyclonal antibody SCRR-1001 recognizing the $\mathrm{N}$ terminus of the rod domain of nestin identifies a series of bands on the same blot (supplemental Fig. 1, available at www.jneurosci.org as supplemental material), suggesting that the sample undergoes proteolysis on isolation (Lendahl et al., 1990). SCRR-1001 appears to recognize the same band as $4 \mathrm{E} 2$ on the blots, suggesting that $4 \mathrm{E} 2$ recognizes an N-terminal containing fragment, but, unlike 4E2, SCRR-1001 recognizes higher-molecular-weight nestin fragments (supplemental Fig. 1, available at www.jneurosci.org as supplemental material). The exact reason why $4 \mathrm{E} 2$ recognizes a nestin fragment but not the native protein or other large fragments that contain the $\mathrm{N}$ terminus is unclear but suggests that some special epitope is present on the prominent fragment it does recognize. The labeling observed with $4 \mathrm{E} 2$ in muscles as well as in cultured myotubes (data not shown) suggests that this nestin epitope in present in vivo and that it is in filaments.

\section{Results}

At neuromuscular junctions, nestin is confined to the postsynaptic apparatus

We investigated the localization of nestin immunoreactivity in nerves and muscles of the rat and mouse using four different anti-nestin antibodies. One of these, the monoclonal antibody $4 \mathrm{E} 2$, was typically used for labeling rat muscle; this antibody appears to recognize a truncated nestin protein (see Materials and Methods). As reported previously for 4E2 (Astrow et al., 1992, 1994) and in agreement with work of others (Carlsson et al., 1999; Vaittinen et al., 1999), we find that immunoreactivity for nestin is concentrated in the postsynaptic apparatus at the nmj and at the myotendinous junction.
To map more precisely the location of nestin immunoreactivity at the nmj, we imaged junctions both en face (Fig. $1 A$ ) and from the side (Fig. $1 E$ ) using confocal microscopy and high numerical aperture objectives. Similar results were obtained with the antibodies in mouse and in rat. Viewed en face, nestin immunoreactivity presented a negative image of the pretzel-like pattern of AChRs concentrated in synaptic gutters underneath the branches of the nerve terminal. The negative image results from the prominent nestin staining in the muscle cytoplasm located between these synaptic gutters (Fig. $1 \mathrm{~A}$, arrowhead) as well as at the edges of these gutters (Fig. $1 D$, arrowhead). A gap of $\sim 1 \mu \mathrm{m}$ with a paucity of nestin label was present between the label for $\mathrm{AChR}$ and an intense band of nestin at the edges of each gutter (Fig. $1 A-D$; arrowhead in $D$ ). Nestin immunoreactivity is also located beneath the synaptic gutters (Fig. 1C). Here the staining has the appearance of bands and more intense puncta. The nestin bands generally run parallel to the bands of AChR (Fig. 1B). These AChR bands represent a diffraction-limited view of the openings of the secondary (junctional) folds that are present in the sacrolemma underneath the nerve terminal (Marques et al., 2000). The puncta of nestin staining are commonly situated between the bands of AChR labeling (Fig. 1, compare B, $C$ ), i.e., in the position of the protrusions of muscle cytoplasm between the secondary folds, the so-called "interfolds" (Couteaux and Spacek, 1988). Last, nestin extends away from the synaptic structures to muscle nuclei located at the synapses (Fig. $1 \mathrm{~A}$, arrow) and to the Z-lines located at the muscle sacrolemma, structures known as costameres (cf. Ervasti, 2003). This latter labeling vanishes within a few micrometers of the junction, either along the long axis of muscle fiber or into the depth of the fiber.

Images of junctions lying on the edge of a muscle fiber (Fig. $1 E-H)$ and thus viewed from the side confirmed the localization of staining obtained from en face views. The gap between AChR and nestin seen at the edge of the synaptic gutters was also present here. Thus, the gap outlines the entire gutter. To investigate whether the gap might be occupied by the secondary, junctional folds, double immunolabeling was performed with an antibody to sodium channels or to the ankyrin protein known to anchor these channels to the cytoskeleton. Both antibodies are known to label the bottoms and sides of junctional folds (Flucher and Daniels, 1989). The ankyrin label occupies the gap between the AChR and the intense nestin label (Fig. $1 E-H$ ). Similar results were obtained with an antibody to sodium channels (data not shown). Thus, an intense band of nestin labeling exists immediately beneath the junctional folds. Fingers of labeling are seen to penetrate toward the synaptic cleft (Fig. $1 E$, arrows in inset), suggesting that nestin immunoreactivity penetrates into the cytoplasm between the junctional folds. These findings suggest that most of the nestin immunoreactivity is not directly associated with the postsynaptic receptors, although, as suggested previously on the basis of electron microscopy, IFs may make attachments to the postsynaptic thickening at the top of the junctional folds (Ellisman et al., 1976). Together, these observations show that nestin is intimately associated with structural elements that define the synaptic contact. Nestin filaments are positioned so that they could support a number of features of the synapse, including junctional folding, the anchoring of synaptic nuclei, and the anchoring of the synaptic site to the membrane cytoskeleton and its attachments to the basal lamina. 

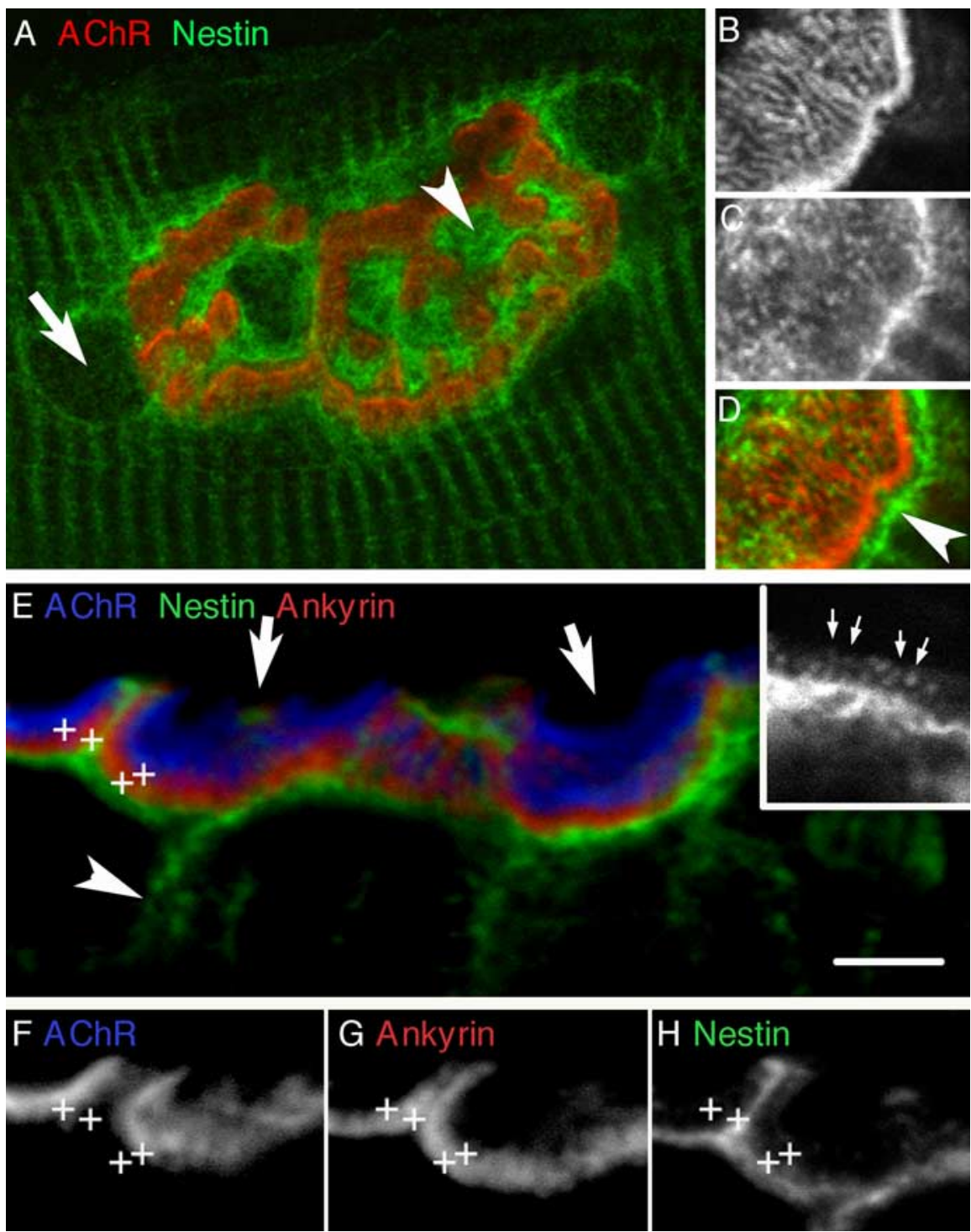

Figure 1. $\boldsymbol{A}-\boldsymbol{H}$, Confocal images of nmjs viewed en face $(\boldsymbol{A}-\boldsymbol{D})$ and from the side $(\boldsymbol{E}-\boldsymbol{H})$ showing the location of nestin immunoreactivity. $\boldsymbol{A}, \mathrm{nmj}$ from the extensor digitorum longus muscle of an adult rat (maximum projection of z-stack) labeled with fluorescent bungarotoxin (red), the anti-nestin antibody mAb 4E2, and a fluorescein-secondary antibody (green). Nestin immunoreactivity surrounds AChRs and extends along sarcomeric, Z-lines confined to the vicinity of the synapse and the surface of the muscle fiber. Nestin also surrounds junctional nuclei (one indicated with arrow in $\boldsymbol{A}$ ). Nestin localizes prominently to the edges of the gutters containing AChR and fills many of the spaces between adjacent gutters (arrowhead in $\boldsymbol{A}$ ). $\boldsymbol{B}-\boldsymbol{D}$, Higher-magnification, maximum projections of a portion of the synaptic gutter in an adult rat soleus muscle. Rhodamine bungarotoxin (white in $\boldsymbol{B}$, red in $\boldsymbol{D})$ shows the bands of receptors indicating the position of the mouths of the secondary folds of the junctional membrane. The fluorescein label for nestin (white in $\boldsymbol{C}$, green in $\boldsymbol{D}$ ) labels structures beneath the synaptic gutter (as determined by examining sequential images in the z-stacks). At the edge of the synaptic gutter, nestin immunoreactivity is displaced from the receptors by $\sim 1 \mu \mathrm{m}$ (arrowhead in $\boldsymbol{D}$ ), suggesting that a space exists between the receptors present near the tops of the folds and most of the nestin network. $\boldsymbol{E}$, Image (maximum projection of 2 slices from a z-stack) of an nmj on the side of a muscle fiber labeled with (y5 bungarotoxin (colored blue in image), the mAb 4E2 anti-nestin antibody (green), and a polyclonal antibody to ankyrin (red), a protein known to be concentrated near the bottoms of the synaptic folds. The blue, red, and green appear in primarily nonoverlapping bands at the synapse. $\boldsymbol{F}-\boldsymbol{H}$, Separate views of the three labels in the left portion of $\boldsymbol{E}$. Fiduciary marks (+ symbols) were placed in the same positions in $\boldsymbol{E}-\boldsymbol{H}$; examination of these marks shows the ankyrin label $(\boldsymbol{G})$ is interposed between the receptors $(\boldsymbol{F})$ and the band of nestin label $(\boldsymbol{H})$. Depressions in the side views of the AChR in $\boldsymbol{E}$ indicate cross-sections of the primary synaptic gutters (arrows). The nestin immunoreactivity surrounds a nucleus (arrowhead). Note that, although the most intense labeling for nestin is at the bottoms of the secondary folds, weaker nestin labeling does extend as periodic protrusions from this more intense labeling to near the AChR. This is most easily seen in the inset in $\boldsymbol{E}$, showing the nestin label in a single, fortuitous z-section of this junction whose brightness and contrast have been adjusted so that the stronger nestin labeling beneath the gutters is saturated. Small arrows identify these protrusions into the layer of AChR. Scale bar: (in $\boldsymbol{E}) \boldsymbol{A}, 9.4 \mu \mathrm{m} ; \boldsymbol{B}-\boldsymbol{D}, 5.3 \mu \mathrm{m} ; \boldsymbol{E}, 2.5 \mu \mathrm{m}$.
Nestin is present in myelinating but not terminal Schwann cells in innervated muscle

As reported previously (Friedman et al., 1990), nestin immunoreactivity was found in myelinating Schwann cells (mSCs) (Fig. $2 B, C$ ). Images of small bundles of axons teased from the sciatic nerve or of intramuscular nerve branches showed that this immunolabeling was strong near the cell bodies of mSCs and at paranodes. Nestin immunolabeling was also present in ribbons, known as Cajal bands, located along internodes (Fig. $2 B$, arrowheads). Labeling with antibodies against both nestin and a general Schwann cell cytoplasmic marker, the protein S100B, showed that these nestin ribbons were contained within the thicker cytoplasmic processes of SCs located on the abaxonal surface of these internodes (Fig. $2 B, C)$.

Despite the presence of nestin in mSCs, no immunoreactivity was detected in the nonmyelinating, $\mathrm{tSC}$ s that cover the nerve terminals at the nmj (Fig. 2D-F).

\section{Nestin immunoreactivity is restricted postsynaptically to neuromuscular junctions during early postnatal development, and denervation arrests this restriction}

To examine how nestin immunoreactivity appears at junctions during development, immunolabeling was performed using the 4E2 antibody on rat muscles during early postnatal development. Immunoreactivity was present in the center of each muscle fiber at postnatal day $0(\mathrm{P} 0)$ as well as at the tendons, but, unlike the distribution in adult muscles, labeling extended longitudinally along the fibers for a considerable distance from the plaques of AChRs (supplemental Fig. $2 A$, available at www. jneurosci.org as supplemental material). In these fibers, there was no obvious preferential localization to the junction. Indeed, in contrast to adult muscles, the locations of junctions could not be reliably identified by the nestin label, and, very often, the brightest label was at sites near but in no obvious relationship to the junctions. In addition labeling was obvious in thin, secondary myotubes that were growing longitudinally in each direction toward the tendons; labeling was particularly strong at the tapered ends of these developing fibers as well as sites in which other fibers had come in contact with the tendons. Later in postnatal development (P10), the labeling in the center of the muscle became confined to regions closer to the AChR plaque (supplemental Fig. 

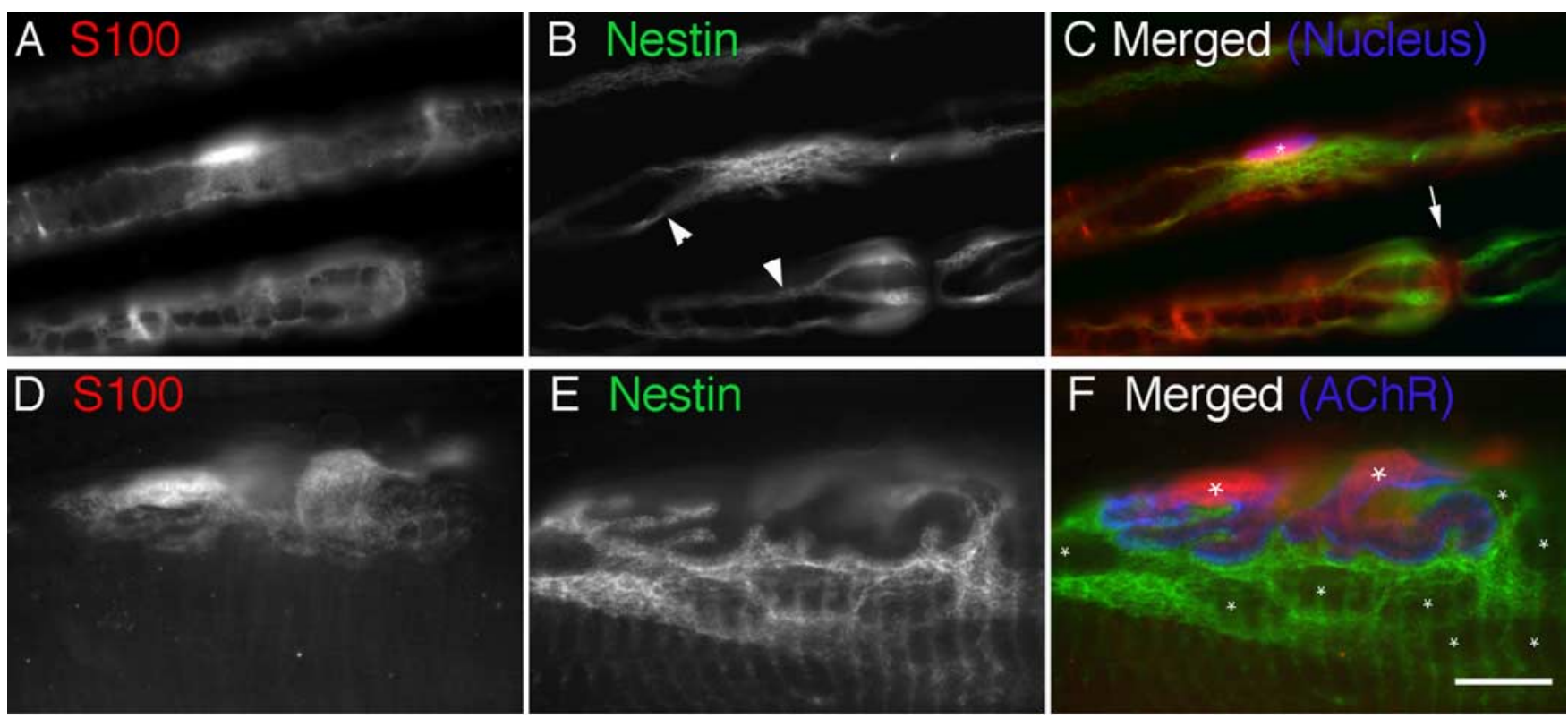

Figure 2. Nestin immunoreactivity is present in myelinating Schwann cells of the nerve but is not detectable in terminal Schwann cells that cover the neuromuscular junction. $A-C$, Image from a teased rat sciatic nerve. $\boldsymbol{D}, \boldsymbol{E}$, Image of a neuromuscular junction from an adult rat soleus muscle. $\boldsymbol{A}, \boldsymbol{D}$, Labeling with antibody to the SC marker S100B. $\boldsymbol{B}, \boldsymbol{E}$, Labeling with antibody $4 \mathrm{E} 2$. $\boldsymbol{C}, \boldsymbol{F}, \mathrm{Color}$ images merged from $\boldsymbol{A}, \boldsymbol{B}$ and $\boldsymbol{D}, \boldsymbol{E}$, respectively, and including, in addition in blue, the nuclear marker $4^{\prime}, \boldsymbol{6}^{\prime}$-diamidino-2-phenylindole $(\boldsymbol{C})$ and $\alpha$-bungarotoxin-labeled $A C h R s(\boldsymbol{F})$. Asterisks indicate cell nuclei, the arrow in $\boldsymbol{C}$ indicates a node of Ranvier, and arrowheads in $\boldsymbol{B}$ indicate bundles of nestin filaments located within S100-labeled thickenings of $S C$ cytoplasm on the abaxonal surface of the internode. Scale bar: $\mathbf{A}-\mathbf{C}, 5 \mu \mathrm{m} ; \mathbf{D}-\boldsymbol{F}, 7.5 \mu \mathrm{m}$.

$2 B$, available at www.jneurosci.org as supplemental material). By $\mathrm{P} 21$, the labeling resembled that reported above in adult muscles (data not shown). If muscles were denervated at the time of birth and examined 2 weeks later, the distribution of nestin immunoreactivity vis-à-vis the $\mathrm{AChR}$ plaques was like that present at the time of denervation (supplemental Fig. 2C, available at www. jneurosci.org as supplemental material), i.e., all along the muscle fibers, showing that the localization of nestin to junctions during development requires innervation.

In adult rodents, denervation causes a rapid reduction of nestin immunoreactivity in the postsynaptic muscle fiber, its appearance in terminal Schwann cells, and its upregulation in Schwann cells of the nerve

In confirmation of previous results using the $4 \mathrm{E} 2$ antibody (Astrow et al., 1994), we found that denervation caused loss of nestin immunoreactivity from the postsynaptic muscle fiber and its appearance in tSCs. Postsynaptic immunoreactivity like that seen in Figure 1 rapidly diminishes in denervated rat muscles and is almost undetectable in most muscle fibers by day 3 (Fig. 3 ). Similar observations were made in mouse muscles in which the decline in postsynaptic immunoreactivity was obvious but less pronounced than in the rat. We confirmed these results using the three other nestin antibodies (data not shown). This contrasts to tSCs, which change from immunonegative (Fig. $2 D-F$ ) to strikingly immunopositive over the same period of time. We previously used this immunoreactivity with the antibody 4E2 to visualize the processes extended by SCs after denervation (Son and Thompson, 1995a,b). The mSCs along the intramuscular nerves that were weakly labeled before denervation become more strongly immunopositive after denervation (data not shown). As the junctions become reinnervated, the normal distribution of nestin immunoreactivity is restored (Astrow et al., 1994) (Fig. 4). An absence of nestin expression in tSCs was seen at neonatal junctions, and these neonatal cells also became immunoreactive after denerva-

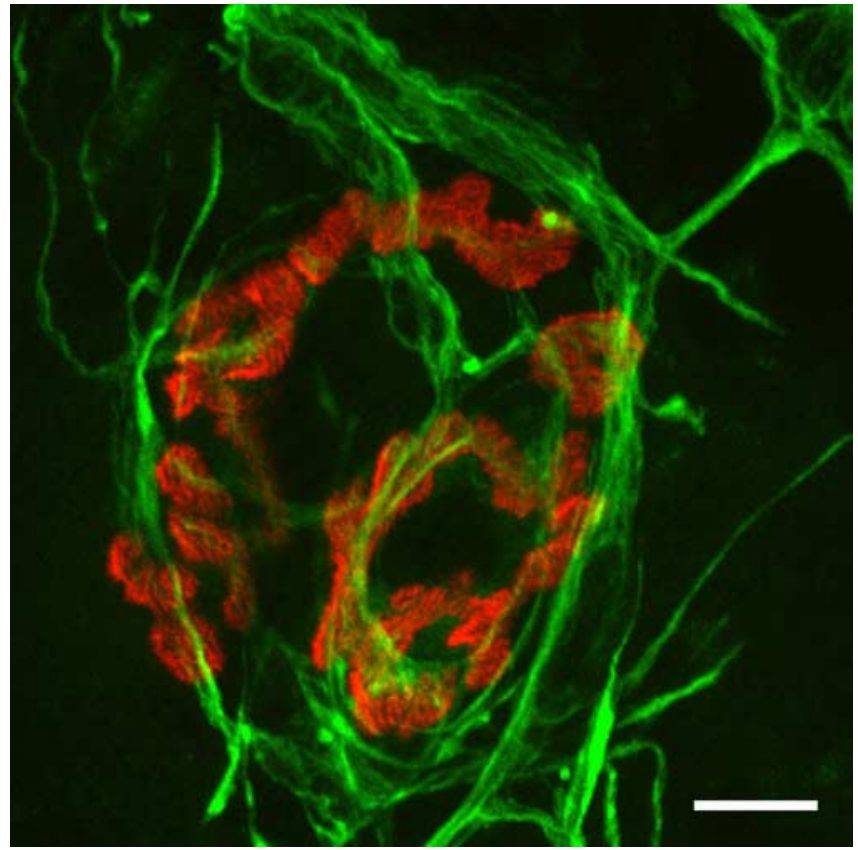

Figure 3. After denervation, nestin immunoreactivity disappears from the postsynaptic apparatus in rat muscle but appears in terminal Schwann cells. Maximum projection of confocal images of the nmj of an adult rat soleus muscle denervated by resection of the sciatic nerve $3 \mathrm{~d}$ earlier. The immunoreactivity for nestin (4E2) is present in the processes of $\mathrm{tSC}$, as determined by colabeling of the SC marker S100B (data not shown); the cell bodies of the $\mathrm{SC}(\mathrm{S}$ are only weakly labeled. Immunoreactivity in the postsynaptic muscle fiber is very weak or absent, in contrast to innervated fibers (Fig. 1). Scale bar, $10 \mu \mathrm{m}$.

tion (supplemental Fig. 4, available at www.jneurosci.org as supplemental material). Thus, unlike the muscle expression, nestin expression in tSCs mirrors the adult pattern from the time of birth. 

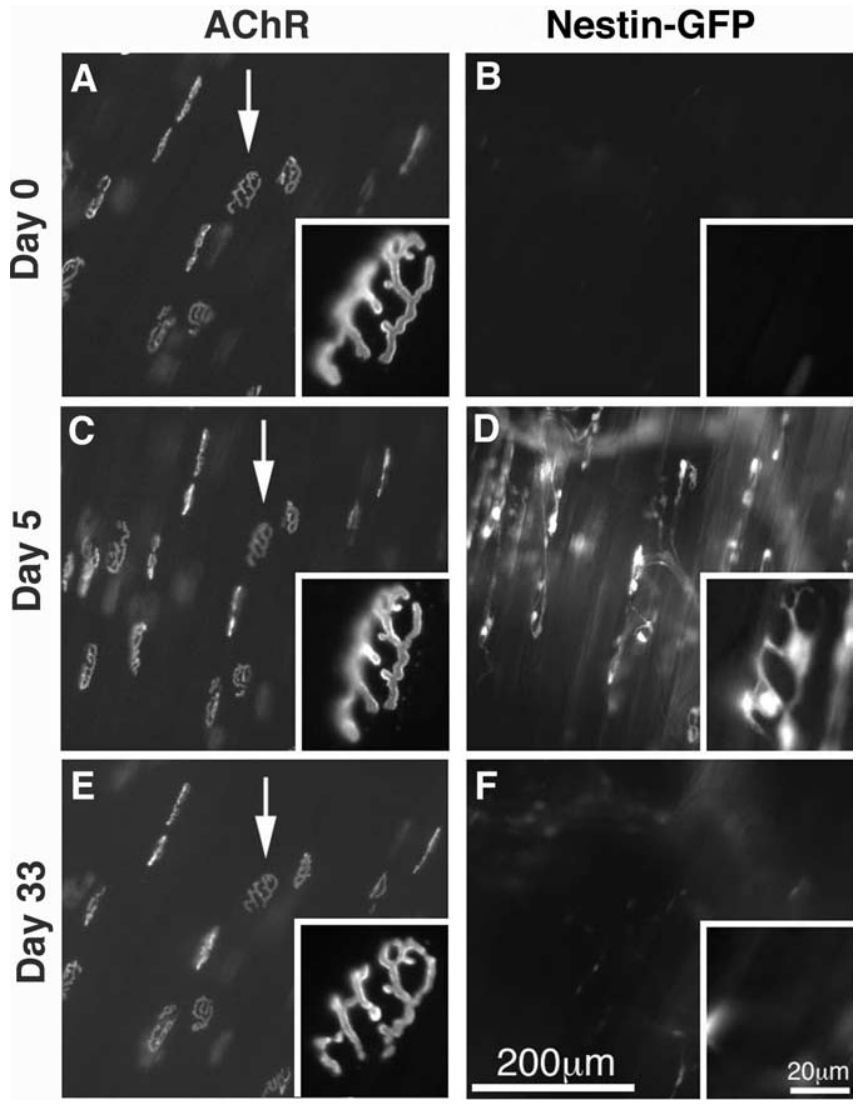

Figure 4. Denervation causes expression of a GFP reporter controlled by the nestin neural enhancer in terminal Schwann cells that persists until the nerve regenerates. $\boldsymbol{A}-\boldsymbol{F}$, Wide-field fluorescence images were captured vitally from the same, small region of the surface of the sternomastoid muscle before denervation (Day 0, $\boldsymbol{A}, \boldsymbol{B}$ ) and $5 \mathrm{~d}$ (Day 5, C, D) and $33 \mathrm{~d}$ (Day 33, $\boldsymbol{E}$, $F)$ after crush of the muscle nerve. Other experiments show the nerve regenerates to this muscle within $10 \mathrm{~d}$ after crush. At each time point, an image was collected of the AChRs labeled with a nonblocking concentration of rhodamine bungarotoxin $(A, C, E)$ and an image of the GFP fluorescence in the same field $(\boldsymbol{B}, \boldsymbol{D}, \boldsymbol{F})$. Arrow marks an endplate shown at higher magnification in the insets in both the AChR and nestin-GFP panels. Before denervation, there is little GFP fluorescence, even postsynaptically in muscle fibers. Within 5 d of denervation, GFP is expressed in SCs above the junctional sites as well as in the intramuscular nerves (out of focus in background of $\boldsymbol{D}$ ). In contrast to the nestin seen by immunostaining (Fig. 3), the soluble GFP fills the cell bodies and nuclei of the SCS. The expression of GFP is greatly diminished by day 33, $>3$ weeks after this region of the muscle is reinnervated. Scale bars: $200 \mu \mathrm{m}$; insets, $20 \mu \mathrm{m}$.

Expression of GFP under the control of the nestin promoter and neural enhancer can be used to vitally observe the reaction of terminal Schwann cells to denervation

To examine the possibility that a mouse line bearing a transgene containing the nestin promoter and intronic neural enhancer coupled to the coding sequence for soluble GFP (Mignone et al., 2004) might label muscle fibers and/or their SCs, we conducted repeated, vital imaging of junctions in the sternomastoid muscle of these mice using techniques developed by Lichtman et al. (1987). We identified nmjs by labeling with a low, nonblocking concentration of rhodamine-bungarotoxin (cf. Rich and Lichtman, 1989; Akaaboune et al., 1999). Before denervation, we could detect no GFP in mSCs, tSCs, or muscle fibers (Fig. $4 B$ ). Only rare, unidentified cells in the connective tissue in the muscle were GFP positive (data not shown). However, if we reimaged muscles within $2 \mathrm{~d}$ of denervation, bright GFP fluorescence was present in both mSCs and tSCs and the processes they extended over and beyond the denervated junction (Fig. $4 D$ ). The number of junctions with GFP-positive cells and the intensity of their label in-
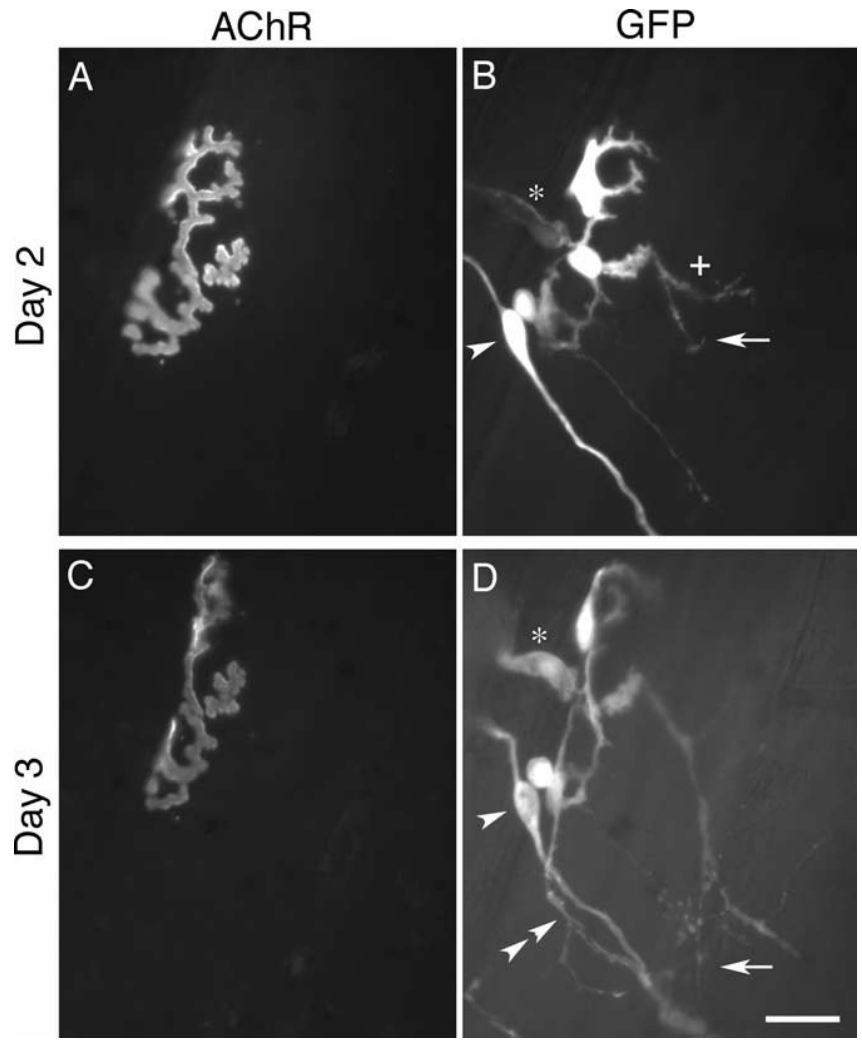

Figure 5. The dynamics of processes formed by terminal Schwann cells after denervation can be vitally imaged in mice that have a nestin enhancer-GFP transgene. $A-D$, Vital images acquired using a rhodamine filter set to image $A C h R(A, C)$ and a GFP filter set $(B, D)$. The same denervated junction was imaged $2 \mathrm{~d}(\boldsymbol{A}, \boldsymbol{B})$ and $3 \mathrm{~d}(\boldsymbol{C}, \boldsymbol{D})$ after section of the muscle nerve. The axon innervating this particular junction arrived over the pathway of an endoneurial tube whose mSCs express GFP (asterisk in $\boldsymbol{B}, \boldsymbol{D}$ ). An unidentified cell is present in each GFP image (arrowhead). Although the $\mathrm{SC} C \mathrm{~s}$ remain associated with the AChRs at each time, they also grow processes away from the endplate. A process extended before day 2 (arrow in $\boldsymbol{B}$ ) has grown an additional $75 \mu \mathrm{m}$ by day 3 (arrow in $\boldsymbol{D}$ ); a process that was absent at day 2 has grown from the synaptic site by day 3 , extending $\sim 75 \mu \mathrm{m}$ (double arrowhead in $\boldsymbol{D}$ ); a branch of a process at day $2(+$ symbol in $\boldsymbol{B})$ is absent at day 3. Scale bar, $12.5 \mu \mathrm{m}$.

creased over the next day (data not shown). The GFP label persisted throughout the period of denervation but then generally disappeared as nerve fibers regenerated and reinnervated the old synaptic sites (Fig. 4F). High-magnification examination of such junctions in vivo showed that the processes extended by tSCs during denervation could be easily identified (Fig. $5 B, D$ ). When we compared the immunostaining of these processes with antinestin antibody and the fluorescence from GFP, we saw that the same processes were labeled but that the GFP label extended slightly $(\sim 5 \mu \mathrm{m})$ beyond the labeling with the nestin antibody, suggesting that cytoplasmic GFP fills the tips of processes beyond the placement of nestin filaments (supplemental Fig. 3, available at www.jneurosci.org as supplemental material). Moreover, the vital imaging revealed that $\mathrm{tSC}$ processes are quite dynamic. Within an interval as short as $24 \mathrm{~h}$, some processes disappeared, others had grown distances of up to $75 \mu \mathrm{m}$, and new processes had appeared (Fig. 5D). After denervation, bright GFP fluorescence also appeared in the mSCs contained within the endoneurial tubes leading to each endplate as well as in the intramuscular nerves (Figs. $4 D, 5 B, D$, asterisks). These results suggest that the so-called neural enhancer present in the nestin gene (Zimmerman et al., 1994) drives expression in SCs after the removal of axons. Because the GFP expression reports the activity of the 
nestin enhancer elements, these observations also suggest that the regulation of nestin expression in tSCs occurs at the transcriptional level.

Although GFP was absent from the tSCs at junctions of neonatal nestin-GFP mice, it was induced after denervation, showing a change in transcriptional activity in SCs at this earlier developmental stage like that in the adult (supplemental Fig. 4, asterisks, available at www.jneurosci.org as supplemental material). This GFP induction occurred before the death of these cells that follows neonatal denervation (Trachtenberg and Thompson, 1996).

\section{Absence of GFP expression in innervated muscle in nestin transgenic mice shows that control elements other than the neural enhancer dictate postsynaptic expression}

There was no GFP evident in the postsynaptic apparatus of the nestin-GFP transgenic mice either before or after denervation. However, because GFP is a soluble protein, any postsynaptic expression might be diluted by the large cytoplasmic volume of the muscle fiber. To test this possibility, we conducted experiments using a second transgenic mouse with an identical promoter and intronic sequences but whose reporter was CFP with a nuclear localization signal. When we imaged normally innervated muscles from this mouse, we saw no nuclear labeling except for rare elongated nuclei that appeared to be apposed to the surface of muscle fibers (data not shown). No labeling was seen at nmjs or in intramuscular nerves. However, after denervation, CFP-labeled nuclei were found in these two locations (supplemental Fig. 5, asterisks, available at www.jneurosci.org as supplemental material). These nuclei belong to SCs because they are located within cells labeled by an antibody to an SC marker (the protein S100B). Thus, just as in the case of the cytoplasmic GFP reporter mice, there is an upregulation of expression of a neural enhancerdriven, nuclear-localized CFP reporter in SCs after denervation. The absence of expression of both the cytoplasmic and nuclear reporter postsynaptically in muscle before and after denervation suggest that the neural enhancer present in intron 2 of the nestin gene is responsible for nestin expression in denervated tSCs but not for its expression postsynaptically in muscle fibers.

\section{Nestin mRNA is localized to the postsynaptic apparatus in muscle fibers}

The motor nerve terminal promotes the transcription of a number of genes important for the construction of the synapse from the subsynaptic myonuclei. These "synapse-specific" genes are transcribed far less, if at all, in nuclei elsewhere in the muscle (Sanes and Lichtman, 2001). Such synapse-specific gene expression is thought to be controlled by local signals arising either directly or indirectly from the nerve terminal. To determine whether nestin transcription in each muscle fiber is controlled in a synapse-specific manner, we performed in situ hybridization on rat muscles, using probes for nestin mRNA. A strong signal was obtained from muscle fibers at their nmjs (Fig. 6B). Little or no hybridization was detected outside the synaptic zone, and the hybridization resembles that present at nmjs when probes for the $\alpha$ subunit of the AChR are used (Fig. $6 C$ ). This result provides direct evidence (in addition to that provided by expression arrays) that nestin mRNA is confined to the nmj (Kishi et al., 2005; McGeachie et al., 2005; Nazarian et al., 2005) and that nestin is transcribed in a synapse-specific manner.

In situ hybridization with a probe for nestin mRNA was also performed at nmjs after denervation. Signal was present, but it was not possible to judge whether the signal in the postsynaptic muscle fiber was decreased (data not shown), because the results from the immunostaining and from the GFP transgenic mice predict that expression is increased in the adjoining tSCs. That SCs upregulate nestin mRNA expression is suggested by comparison of the hybridization signal within the intramuscular nerves of denervated but not innervated intramuscular nerves (Fig. $6 D, E)$.

\section{Blockade of transmitter release from the junction upregulates nestin expression in Schwann cells and downregulates this expression in muscle fibers}

The localization of nestin mRNA to the postsynaptic region and the loss of immunoreactivity for nestin protein after denervation suggest a special role for the nerve in regulating nestin expression. To examine the possibility that nerve-evoked activity plays a role in this expression, botulinum toxin was applied topically to the soleus muscle in adult rats and to sternomastoid muscles in mice. Muscles were examined at the time of the terminal experiment by stimulation of the muscle nerve to verify a deficiency in the ability of the motor axons to evoke muscle twitches. When muscles were examined after 3-4 d of blockade, no substantial changes in immunoreactivity in the postsynaptic apparatus or in tSCs were seen. However, after $8-10 \mathrm{~d}$ of blockade of rat soleus, immuno- 
reactivity in the postsynaptic apparatus was diminished $(67 \%$ of junctions in three muscles; data not shown), and immunoreactivity appeared in tSCs and the processes these tSCs extended away from the synaptic sites (63\% of the junctions in three muscles; data not shown). Similar findings were made in the sternomastoid muscles of adult mice probed with a polyclonal antibody to nestin. These findings suggest that transmitter release from the nerve terminal plays a role in maintaining the postsynaptic expression of nestin in muscle and in suppressing it in tSCs.

\section{Stimulation of denervated muscle maintains postsynaptic nestin immunoreactivity but does not prevent the upregulation of nestin expression in terminal Schwann cells} Many of the effects of denervation on muscle gene expression are mediated via the electrical/contractile activity imparted to the fiber by its innervation (Lømo, 1980). To test whether the postsynaptic localization of nestin might be influenced by muscle activity, we denervated rat hindlimb muscles and, at the time of denervation, began extrinsic stimulation of the soleus muscle with currents administered via electrodes placed at the tendon at each end of the muscle. Stimulation of muscles was able to preserve immunoreactivity for nestin at the former synaptic sites (Fig. 7, compare $C, D$ ) for periods of denervation of up to $17 \mathrm{~d}$, the longest periods tested. The same period of denervation resulted in marked diminution in nestin immunoreactivity in muscles that were either not stimulated or that received sham stimulation. We conclude that muscle activity maintains the postsynaptic nestin protein. It may do so by either promoting transcription at the synapse or altering the turnover of nestin protein. In contrast, imposing this activity on denervated muscles did not alter the immunoreactivity appearing in tSCs (Fig. 7D), nor did it apparently alter their extension of processes, as has been reported previously (Love et al., 2003).

\section{Discussion}

Nestin filaments localized to the postsynaptic muscle fiber appear to link several subcellular structures. These filaments are present within the cytoplasm in the synaptic folds and appear to connect to a prominent network of the same filaments that lie beneath the troughs of these folds. These filaments, in turn, appear to connect to a network of nestin-containing filaments that are present at the sacrolemma between the primary synaptic gutters, that surround junctional nuclei, and that are attached to costameric structures at the Z-lines in the vicinity of the junction. These locations suggest a number of possible functions for nestin at the junction. One would be maintenance of the junctional folds themselves. In this regard, it is interesting that nestin becomes localized to the synaptic site during the postnatal period when junctional folds are reported to be first forming (Marques et al., 2000). Arguing against this possibility is the observation that nestin essentially disappears from rat neuromuscular junctions after denervation, whereas the folds persist (Miledi and Slater, 1968), although some observations suggest that these folds begin to change the size of their openings to the synaptic space, their frequency, and the depth of their penetration into the sarcoplasm with longer periods of denervation (Matsuda et al., 1988). Froehner et al. (1987) suggested the possibility that the intermediate filament desmin, which is also localized to the junction, might be involved in postsynaptic folding but primarily discounted this possibility because this filament is present at junctions that have no synaptic folds. Although deletion of desmin in mice is reported to present no neuromuscular phenotype, nestin IFs remain assembled within the synaptic folds (Carlsson et al., 1999). A second possible

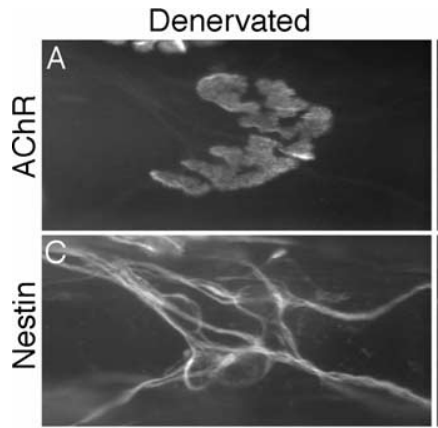

Denervated + Stimulated
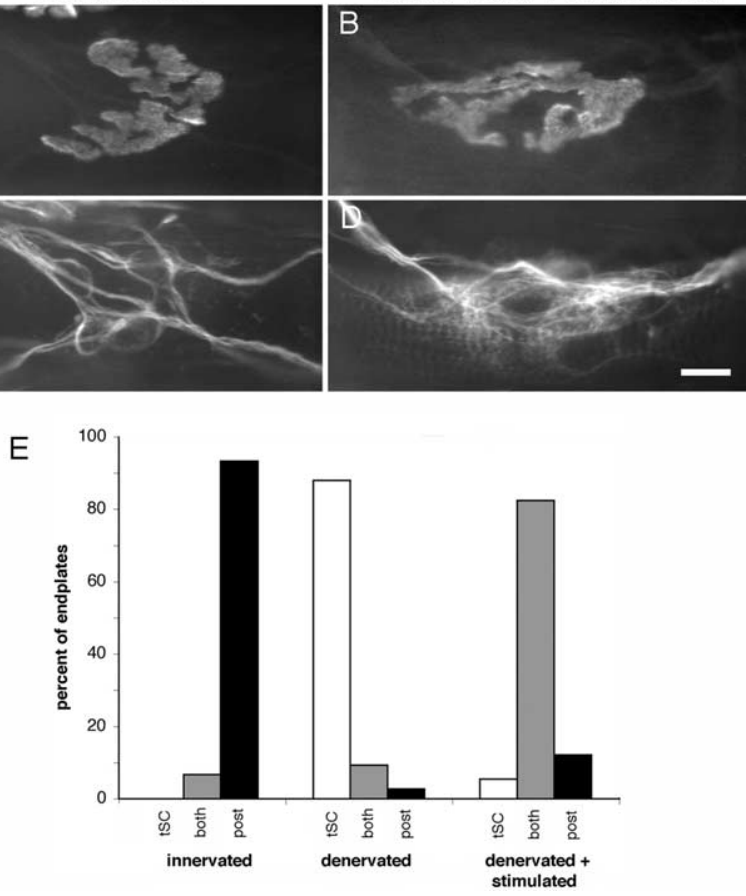

Figure 7. Stimulation of denervated muscle maintains postsynaptic immunoreactivity for nestin but does not affect its upregulation in terminal Schwann cells. $\boldsymbol{A}-\boldsymbol{D}$, Junctions in a rat soleus muscles $7 \mathrm{~d}$ after denervation by sciatic nerve resection were identified by labeling of $\mathrm{AChR}$ with rhodamine bungarotoxin $(\boldsymbol{A}, \boldsymbol{B})$ and immunostaining for nestin using the 4E2 antibody $(\boldsymbol{C}, \boldsymbol{D})$. Junction in $\boldsymbol{A}$ and $\boldsymbol{C}$ was from denervated muscle left unstimulated. Junction in $\boldsymbol{B}$ and $\boldsymbol{D}$ was from a muscle of a littermate that was similarly denervated but stimulated directly by implanted electrodes with $100 \mathrm{~Hz}$ trains lasting $1 \mathrm{~s}$ repeated every $100 \mathrm{~s}$ (average frequency, 1 $\mathrm{Hz})$. Although both muscles have labeling in $\mathrm{tSC}$ and the processes they extend from the denervated junction, the stimulated muscle retains postsynaptic labeling whereas the unstimulated muscle has lost it. Scale bar, $10 \mu \mathrm{m}$. $\boldsymbol{E}$, Nestin labeling with mAb 4E2 in three rat soleus muscles from three different animals. Two of the muscles were denervated for $7 \mathrm{~d}$, and one of these was stimulated for the same period of time. Seventy-five junctions in each muscle were scored for the presence of labeling only in $\mathrm{tSCS}$ (white bars), only in the postsynaptic apparatus underneath AChR (black bars), or in both (gray bars). Results shown here were typical of at least five cases in which stimulation was successfully applied for 7-14 d. In a few cases, stimulation was begun some days after loss of postsynaptic immunoreactivity in companion muscles. In these cases, immunoreactivity was restored to the postsynaptic area.

function might be some role in the stabilization of AChRs. Receptors undergo a change in distribution during postnatal development (the plaque-to-pretzel distribution) (Marques et al., 2000) and a change in receptor half-life during synapse formation (Levitt et al., 1980). The turnover rate of receptors increases during denervation or activity block (Levitt et al., 1980; Akaaboune et al., 1999). In this regard, it is interesting that a kinase concentrated at the junction that is indirectly activated by acetylcholine binding/fiber depolarization and is involved in receptor turnover (Lin et al., 2005) also affects nestin turnover (Sahlgren et al., 2003). A third possible function, suggested by the association with ankyrin, is that nestin participates in the localization of voltage-gated $\mathrm{Na}$ channels in the troughs of the synaptic folds (Flucher and Daniels, 1989; Wood and Slater, 1998). Arguing against this possibility is the persistence of such channels after denervation when nestin disappears. A fourth possible function, to anchor junctional nuclei to the synaptic site, also seems unlikely because these nuclei are reported to retain their location, at least in the short term after denervation (Rich and Lichtman, 1989), whereas nestin filaments are essentially lost. A fifth possible function is to assist in providing mechanical stability to the 
synaptic site and even the attachment of the nerve to this site during the stress of muscle contraction. An involvement in mechanical stability is also suggested by the expression of nestin at the myotendinous junction. With many novel functions being attributed to intermediate filaments (Coulombe and Wong, 2004), it will be interesting to investigate the effects of nestin deletion at the nmj.

The results of in situ hybridization with a nestin probe reported here provide additional support for the inclusion of nestin in the set of mRNAs that are selectively transcribed by nuclei located at the synapse. Such selective transcription would explain the synaptic localization of the nestin protein. One of the transcriptional control elements believed to lead to local expression at the synapse is the so-called N-box that binds an Ets transcription factor (Fromm and Burden, 1998). Interestingly, disruption of mRNAs selectively transcribed at the nmj by expression in muscle fibers of a dominant-negative Ets is found to alter junctional morphology and synaptic folding (de Kerchove D'Exaerde et al., 2002). However, nestin is not likely to be one of the mRNAs controlled in this manner, because inspection of the rat and mouse gene sequence reveals no N-box (CCGGAA) in the promoter or intronic sequences (GenBank accession numbers NW_043540 and NW_000191.1). The nestin gene does have a binding site for a second transcription factor, Kaiso, that may involved in synapse-specific expression of the protein rapsyn (Rodova et al., 2004) (but see Prokhortchouk et al., 2006). This sequence (CTGCNA) is found in the first intron of the rat and mouse gene. The relevance of Kaiso for synaptic expression of nestin remains to be determined. Our observations show that a reporter transgene driven by the nestin promoter and neural enhancer contained in the second intron is not expressed in muscle fibers. This provides support for the previous report that nestin control elements in the first intron are responsible for expression in developing skeletal muscle (Zimmerman et al., 1994). This intron may be responsible for synapse-specific expression of nestin mRNA.

Our results suggest that postsynaptic expression of nestin is controlled by nerve-induced muscle activity. Blockade of neuromuscular activity diminishes nestin immunoreactivity in the postsynaptic fiber, and stimulation of denervated muscle is able to maintain it in the absence of the nerve. Thus, nestin joins a set of other costameric proteins whose distribution is regulated by activity (Bezakova and Lomo, 2001). The activity control here has interesting parallels to the activity-dependent regulation of acetylcholinesterase at the rodent $\mathrm{nmj}$ (Rotundo, 2003).

Our experiments also provide evidence concerning the regulation of nestin in SCs and, in particular, in tSCs at the junction. Either denervation or blockade of neurotransmitter release is able to promote the synthesis of nestin within these tSCs. On the basis of observations using nestin-GFP transgenic mice, this regulation involves the nestin neural enhancer. The suggestion is that neurotransmitter release, known to activate signaling in tSCs (Rochon et al., 2001), suppresses the synthesis of nestin in tSCs; this has a parallel in the frog, in which neurotransmitter suppresses the synthesis of glial fibrillary acidic protein (GFAP), another intermediate filament, in tSCs (Georgiou et al., 1994). It has been suggested that this upregulation of GFAP may be involved in the growth response of these cells. This may be the case for nestin as well. Observations in other cells suggest that IFs may be involved in growth regulation (Coulombe and Wong, 2004). Of course, because nestin is also upregulated in SCs of the nerve by denervation in which neurotransmitter release is unlikely, nerve contact may play a role in regulating nestin expression in SCs. It is also possible that other agents known to be released by axons that affect SCs (Fields, 2006) are involved. Still another possibility is that interruption of axonal signaling initiates autocrine signaling mechanisms in SCs that have been shown to promote nestin expression (Hayworth et al., 2006).

The nestin-GFP mice provide a powerful means of observing SCs in the living animal as they respond to denervation. These mice will be of particular use because the GFP driven from another SC promoter, namely S100B, would be expected to be downregulated, like S100B itself, as a consequence of denervation (Perez and Moore, 1968). Use of the nestin transgenics reported here has already shown us just how dynamic these cells are after denervation.

\section{References}

Akaaboune M, Culican SM, Turney SG, Lichtman JW (1999) Rapid and reversible effects of activity on acetylcholine receptor density at the neuromuscular junction in vivo. Science 286:503-507.

Astrow SH, Sutton LA, Thompson WJ (1992) Developmental and neural regulation of a subsarcolemmal component of the rat neuromuscular junction. J Neurosci 12:1602-1615.

Astrow SH, Son Y-J, Thompson WJ (1994) Differential neural regulation of a neuromuscular junction-associated antigen in muscle fibers and Schwann cells. J Neurobiol 25:937-952.

Bezakova G, Lømo T (2001) Muscle activity and muscle agrin regulate the organization of cytoskeletal proteins and attached acetylcholine receptor (AchR) aggregates in skeletal muscle fibers. J Cell Biol 153:1453-1463.

Burden S (1982) Identification of an intracellular postsynaptic antigen at the frog neuromuscular junction. J Cell Biol 94:521-530.

Carlsson L, Li Z, Paulin D, Thornell LE (1999) Nestin is expressed during development and in myotendinous and neuromuscular junctions in wild type and desmin knock-out mice. Exp Cell Res 251:213-223.

Cartaud A, Courvalin JC, Ludosky MA, Cartaud J (1989) Presence of a protein immunologically related to lamin B in the postsynaptic membrane of Torpedo marmorata electrocyte. J Cell Biol 109:1745-1752.

Clarke SR, Shetty AK, Bradley JL, Turner DA (1994) Reactive astrocytes express the embryonic intermediate neurofilament nestin. NeuroReport 5:1885-1888.

Coulombe PA, Wong P (2004) Cytoplasmic intermediate filaments revealed as dynamic and multipurpose scaffolds. Nat Cell Biol 6:699-706.

Couteaux R, Spacek J (1988) Specialization of the subsynaptic cytoplasm. Comparison of axospinous synapses and neuromuscular junctions. In: Cellular and molecular basis of synaptic transmission (Zimmerman $\mathrm{H}$, ed), pp 25-50. Berlin: Springer.

Dahlstrand J, Collins VP, Lendahl U (1992) Expression of the class VI intermediate filament nestin in human central nervous system tumors. Cancer Res 52:5334-5341.

de Kerchove D'Exaerde A, Cartaud J, Ravel-Chapuis A, Seroz T, Pasteau F, Angus LM, Jasmin BJ, Changeux JP, Schaeffer L (2002) Expression of mutant Ets protein at the neuromuscular synapse causes alterations in morphology and gene expression. EMBO Rep 3:1075-1081.

Ellisman MH, Rash JE, Staehelin LA, Porter KR (1976) Studies of excitable membranes. II. A comparison of specializations at neuromuscular junctions and nonjunctional sarcolemmas of mammalian fast and slow twitch muscle fibers. J Cell Biol 68:752-774.

Ervasti JM (2003) Costameres: the Achilles' heel of Herculean muscle. J Biol Chem 278:13591-13594.

Fields RD (2006) Nerve impulses regulate myelination through purinergic signalling. Novartis Found Symp 276:148-158; discussion 158-161, 233237, 275-281

Flucher BE, Daniels MP (1989) Distribution of $\mathrm{Na}^{+}$channels and ankyrin in neuromuscular junctions is complementary to that of acetylcholine receptors and the $43 \mathrm{kd}$ protein. Neuron 3:163-175.

Friedman B, Zaremba S, Hockfield S (1990) Monoclonal antibody rat 401 recognizes Schwann cells in mature and developing peripheral nerve. J Comp Neurol 295:43-51.

Froehner SC, Murnane AA, Tobler M, Peng HB, Sealock R (1987) A postsynaptic $\mathrm{M}_{\mathrm{r}} 58,000(58 \mathrm{~K})$ protein concentrated at acetylcholine receptor-rich sites in Torpedo electroplaques and skeletal muscle. J Cell Biol 104:1633-1646. 
Fromm L, Burden SJ (1998) Synapse-specific and neuregulin-induced transcription require an ets site that binds GABPalpha/GABPbeta. Genes Dev 12:3074-3083.

Gallo V, Armstrong RC (1995) Developmental and growth factor-induced regulation of nestin in oligodendrocyte lineage cells. J Neurosci 15:394-406.

Georgiou J, Robitaille R, Trimble WS, Charlton MP (1994) Synaptic regulation of glial protein expression in vivo. Neuron 12:443-455.

Hayworth CR, Moody SE, Chodosh LA, Krieg P, Rimer M, Thompson WJ (2006) Induction of neuregulin signaling in mouse Schwann cells in vivo mimics responses to denervation. J Neurosci 26:6873-6884.

Hirokawa N, Heuser JE (1982) Internal and external differentiations of the postsynaptic membrane at the neuromuscular junction. J Neurocytol 11:487-510.

Hockfield S, McKay RDG (1985) Identification of major cell classes in the developing mammalian nervous system. J Neurosci 5:3310-3328.

Kachinsky AM, Dominov JA, Miller JB (1994) Myogenesis and the intermediate filament protein, nestin. Dev Biol 165:216-228.

Kang H, Thompson WJ, Mignone J, Enikolopov G (2001) Changes of nestin expression pattern in neonates and adult neuromuscular junction of nestin transgenic mice. Soc Neurosci Abstr 27:694.698.

Karnovsky MJ (1964) The localization of cholinesterase activity in rat cardiac muscle by electron microscopy. J Cell Biol 23:217-232.

Kishi M, Kummer TT, Eglen SJ, Sanes JR (2005) LL5beta: a regulator of postsynaptic differentiation identified in a screen for synaptically enriched transcripts at the neuromuscular junction. J Cell Biol 169:355-366.

Kopp DM, Thompson WJ (1998) Innervation-dependent expression of nestin at the mammalian neuromuscular junction. Soc Neurosci Abstr 24:1038

Lendahl U, Zimmerman LB, McKay RD (1990) CNS stem cells express a new class of intermediate filament protein. Cell 60:585-595.

Levitt TA, Loring RH, Salpeter MM (1980) Neuronal control of acetylcholine receptor turnover rate at a vertebrate neuromuscular junction. Science 210:550-551.

Lichtman JW, Magrassi L, Purves D (1987) Visualization of neuromuscular junctions over periods of several months in living mice. J Neurosci 7:1215-1222.

Lin W, Dominguez B, Yang J, Aryal P, Brandon EP, Gage FH, Lee KF (2005) Neurotransmitter acetylcholine negatively regulates neuromuscular synapse formation by a Cdk5-dependent mechanism. Neuron 46:569-579.

Love FM, Thompson WJ (1999) Glial cells promote muscle reinnervation by responding to activity-dependent postsynaptic signals. J Neurosci 19:10390-10396.

Love FM, Son YJ, Thompson WJ (2003) Activity alters muscle reinnervation and terminal sprouting by reducing the number of Schwann cell pathways that grow to link synaptic sites. J Neurobiol 54:566-576.

Lømo T (1980) Requirements for the formation and maintenance of neuromuscular connections. Curr Top Dev Biol 16:253-281.

Marques MJ, Conchello JA, Lichtman JW (2000) From plaque to pretzel: fold formation and acetylcholine receptor loss at the developing neuromuscular junction. J Neurosci 20:3663-3675.

Matsuda Y, Oki S, Kitaoka K, Nagano Y, Nojima M, Desaki J (1988) Scanning electron microscopic study of denervated and reinnervated neuromuscular junction. Muscle Nerve 11:1266-1271.

McGeachie AB, Koishi K, Andrews ZB, McLennan IS (2005) Analysis of mRNAs that are enriched in the post-synaptic domain of the neuromuscular junction. Mol Cell Neurosci 30:173-185.

Mignone JL, Kukekov V, Chiang AS, Steindler D, Enikolopov G (2004) Neural stem and progenitor cells in nestin-GFP transgenic mice. J Comp Neurol 469:311-324.

Miledi R, Slater CR (1968) Electrophysiology and electron-microscopy of rat neuromuscular junctions after nerve degeneration. Proc R Soc B Biol Sci 169:289-306.

Nazarian J, Bouri K, Hoffman EP (2005) Intracellular expression profiling by laser capture microdissection: three novel components of the neuromuscular junction. Physiol Genomics 21:70-80.

Perez VJ, Moore BW (1968) Wallerian degeneration in rabbit tibial nerve: changes in amounts of the S-100 protein. J Neurochem 15:971-977.

Prokhortchouk A, Sansom O, Selfridge J, Caballero IM, Salozhin S, Aithozhina D, Cerchietti L, Meng FG, Augenlicht LH, Mariadason JM, Hendrich B, Melnick A, Prokhortchouk E, Clarke A, Bird A (2006) Kaisodeficient mice show resistance to intestinal cancer. Mol Cell Biol 26:199-208.

Rich MM, Lichtman JW (1989) In vivo visualization of pre- and postsynaptic changes during synapse elimination in reinnervated mouse muscle. J Neurosci 9:1781-1805.

Rimer M, Prieto AL, Weber JL, Colasante C, Ponomareva O, Fromm L, Schwab MH, Lai C, Burden SJ (2004) Neuregulin-2 is synthesized by motor neurons and terminal Schwann cells and activates acetylcholine receptor transcription in muscle cells expressing ErbB4. Mol Cell Neurosci 26:271-281.

Rochon D, Rousse I, Robitaille R (2001) Synapse-glia interactions at the mammalian neuromuscular junction. J Neurosci 21:3819-3829.

Rodova M, Kelly KF, VanSaun M, Daniel JM, Werle MJ (2004) Regulation of the rapsyn promoter by kaiso and delta-catenin. Mol Cell Biol 24:7188-7196.

Rotundo RL (2003) Expression and localization of acetylcholinesterase at the neuromuscular junction. J Neurocytol 32:743-766.

Sahlgren CM, Mikhailov A, Vaittinen S, Pallari HM, Kalimo H, Pant HC, Eriksson JE (2003) Cdk5 regulates the organization of Nestin and its association with p35. Mol Cell Biol 23:5090-5106.

Sanes JR, Lichtman JW (2001) Induction, assembly, maturation and maintenance of a postsynaptic apparatus. Nat Rev Neurosci 2:791-805.

Sealock R, Murnane AA, Paulin D, Froehner SC (1989) Immunochemical identification of desmin in Torpedo postsynaptic membranes and at the rat neuromuscular junction. Synapse 3:315-324.

Sejersen T, Lendahl U (1993) Transient expression of the intermediate filament nestin during skeletal muscle development. J Cell Sci 106:1291-1300.

Son YJ, Thompson WJ (1995a) Schwann cell processes guide regeneration of peripheral axons. Neuron 14:125-132.

Son YJ, Thompson WJ (1995b) Nerve sprouting in muscle is induced and guided by processes extended by Schwann cells. Neuron 14:133-141.

Trachtenberg JT, Thompson WJ (1996) Schwann cell apoptosis at developing neuromuscular junctions is regulated by glial growth factor. Nature 379:174-177.

Vaittinen S, Lukka R, Sahlgren C, Rantanen J, Hurme T, Lendahl U, Eriksson JE, Kalimo H (1999) Specific and innervation-regulated expression of the intermediate filament protein nestin at neuromuscular and myotendinous junctions in skeletal muscle. Am J Pathol 154:591-600.

Wood SJ, Slater CR (1998) $\beta$-Spectrin is colocalized with both voltage-gated sodium channels and ankyring at the adult rat neuromuscular junction. J Cell Biol 140:675-684.

Zimmerman L, Parr B, Lendahl U, Cunningham M, McKay R, Gavin B, Mann J, Vassileva G, McMahon A (1994) Independent regulatory elements in the nestin gene direct transgene expression to neural stem cells or muscle precursors. Neuron 12:11-24.

Zuo Y, Lubischer JL, Kang H, Tian L, Mikesh M, Marks A, Scofield VL, Maika S, Newman C, Krieg P, Thompson WJ (2004) Fluorescent proteins expressed in mouse transgenic lines mark subsets of glia, neurons, macrophages, and dendritic cells for vital examination. J Neurosci 24:10999_ 11009. 